\title{
Establishment on Evaluation Indicator System for Comprehensive Ability of Coach
}

\author{
Guoquan Zhang \\ Department of Physical Education, Bohai University, Jinzhou, 121013, China \\ 673722120@qq.com
}

Keywords: coach; comprehensive ability; system evaluation; indicator system; KLEE

\begin{abstract}
Comprehensive evaluation is an effective means to improve coach' abilities. In this paper, research based on system analysis method, provide support for comprehensive ability of coach. It based on indicator system establish principle, initially establish evaluation indicator system which include 6 one-level indicator and 24 second-level indicator using hierarchical level analysis model, establish weight calculation mathematical model based on KLEE law, and calculate one-level indicator and various secondary indicator weights, preliminary indicator system and weights together constitute complete indicator system. The result show that the research method is scientific, calculation simple, build indicator system content comprehensive, operability powerful, play an important action to promotion of coach's ability.
\end{abstract}

\section{Introduction}

Coach as a component of the school education system, has education evaluation in common, also has a professional sport personality. coach evaluation method based on the basic theory of modern education evaluation, use physical education evaluation practice need as a starting point, the method by means of education statistics and measurement, pedagogic, education management, psychology and other disciplines of knowledge, through education evaluation practice test, filter, modify, and improve the system after the formation[1,2]. Indicator system establishment is a system evaluation's basic work. In this paper, the initial establishment of evaluation indicator system of coach, calculate the weight of indicator system, provide support for evaluation of coach. At the same time, identify the impact of the main indicators of the ability of coach, improve their ability in Coach and sport teachers in the organization and management of the process of focusing on these indicators, in order to improve the standard of sport education.

\section{Establishment Principle on Indicator System}

Coach evaluation is a complex organizational activities, must follow certain standard of conduct. Only define PE Teacher evaluation principle, in order to ensure normalization and scientific evaluation of Coach. Which based on the evaluation of the nature of understanding of the law, PE teacher's work task, work characteristic and related research achievement on evaluation principle, combined with Coach assessment practice objective need, construction of evaluation indicator system of Coach should follow the following principles [3]:

Direction combines with the main in principle. Coach evaluation adhere to the correct orientation, must adhere to the teacher-centered, full respect for the dominant position of teachers, maximize teachers' creativity, constantly stimulate the inner motivation of teachers.

Scientific combines with feasibility in principle. Evaluation activity use the theories of modern education theory as a guide, develop and implement program evaluation must be based on reality, use scientific evaluation technique and method. In adhering to the scientific, must also consider the feasibility.

Static combines with dynamic in principle. Static evaluation facilitate horizontal comparison, only consider real state at a particular time and space to evaluation object, dynamic evaluation focus on longitudinal comparison, pay attention to the development potentiality and trend. In order to 
better complete the evaluation, only combine the two together.

Reward and punishment combine with development in principle. Reward and punishment and development is the essential attribute evaluation. Evaluation of reward and punishment help eliminate egalitarianism, have certain incentive function, evaluation of developmental can achieve double win results and common development of teachers and schools. It want to balance the reward and punishment of the functions and development of functional needs based on objective and subjective evaluation purpose.

Qualitative analysis combine with quantitative analysis in principle. Qualitative analysis is the basic prerequisite for quantitative analysis, there is no qualitative and quantitative is blind, worthless quantitative, qualitative and quantitative analysis to make it more scientific and accurate, promote wide-ranging and in-depth qualitative analysis of the conclusions drawn. Both complement each other, which based on qualitative and quantitative, qualitative and quantitative is specific, combine them flexibly in order to achieve the best result.

\section{Initial Establishment on Indicator System}

Complex issues decision involve many indicators, and there are complex relationship between indicators, the indicators relate to the well-organized, hierarchical, construct a structural indicator system structure model, is an effective way to solve complex problem. The usual practice is dividing indicator into a number of levels, the upper indicator play a dominant role play to lower indicator, this top-down hierarchical structure is called hierarchical structure. Hierarchical structure can generally be divided into the top of the intermediate layer, middle layer and bottom layer. In the full investigation based on the analysis, combine with results of previous studies, construction of indicator system hierarchical structure model show in Fig. 1.

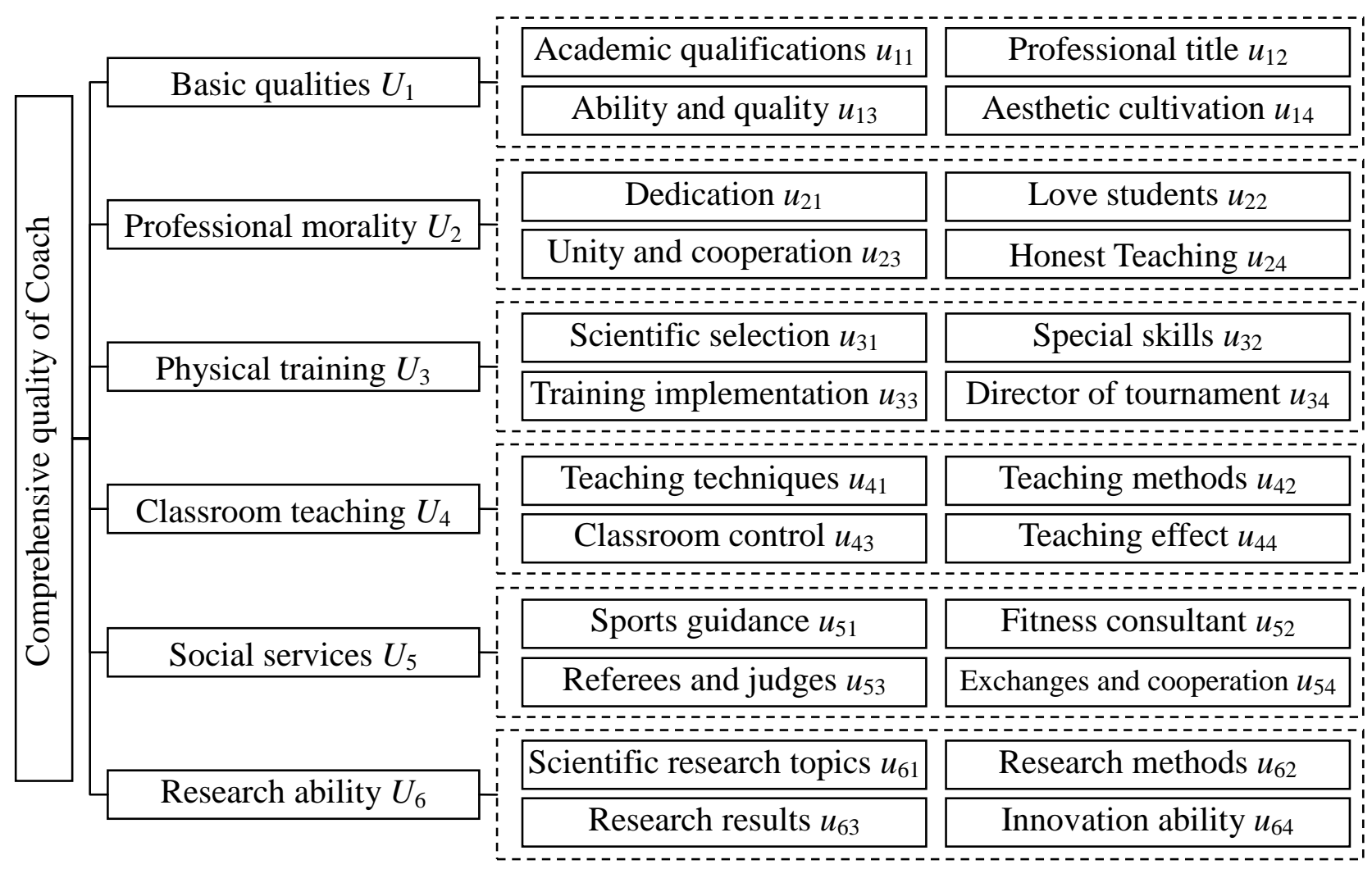

Fig. 1. Evaluation index system on comprehensive quality of Coach

Green Building Materials evaluation index system of figure 1 includes six level indicators, each level indicators also contains four secondary indexes, each index briefly described as follows[4-7]:

Basic qualities. Determine the quality of education is the core of teacher quality, including many aspects of ideological and political qualities, moral and cultural qualities, intelligent quality, psychological, physical, external quality and so on. Coach basic qualities sum up as "Academic 
qualifications, Professional title, Ability and quality, Aesthetic cultivation" four indicators.

Professional morality. It is closely in line with ethical guidelines and professional characteristics required for people with occupational activities, the sum of morality and moral character. Teachers' professional ethics is teachers engage in moral education work in the code of conduct and follow necessary. Coach' professional ethics are summarized as "Dedication, Love students, Unity and cooperation, Honest Teaching" and other four indicators.

Physical training. Exercise training is a major component of competitive sport, only the full and scientific sport training are able to play athletes athletic ability, sport training content and arrangement must comply with the characteristics of sport and competition rule. Sports training capacity of Coach are summed up as "Scientific selection, Special skills, Training implementation, Director of tournament" and other four indicators.

Classroom teaching. It is a means commonly used in education, is a target clear, accord to plan, organize, step by step process of bilateral activities of teachers teaching and learning students learn a combination of bilateral active process. Classroom Teaching is investigating teacher's fundamental indicator. Coach classroom teaching ability are summed up as "Teaching techniques, Teaching methods, Classroom control, Teaching effect" and other four indicators.

Social services. Coach not only have wealth of theoretical knowledge, but also have experience to carry out sports competitions, organization experienced sports activities, can be enjoyed by the masses of the project to compose and organizational management of sports competitions planning, program, organization and implementation. Coach social service ability are summed up as "Sports guidance, Fitness consultant, Referees and judges, Exchanges and cooperation" and other four indicators.

Research ability. Strengthening research capacity of Coach training, improve the scientific level of teaching and training, is needs of carrying out the modern teaching. Increase research capacity should expand their knowledge, improve professional capacity, enhance creative talent, participate in academic activities. Coach research capacity are summarized as "Scientific research topics, Research methods, Research results, Innovation ability" and other four indicators.

\section{Mathematical Model on Weight Calculation}

Using indicator system to comprehensive evaluation, relative importance degree are different from each indicator, the relative importance degree of such indicators is called the weight or size of the weighting factor. Different weights will get different evaluation results, so determine a reasonable weight is an important issue of the indicator system. There are many ways to determine the weight, the more common are: direct judgment method, delphi method, gathering statistics iterative method, adjacent index comparison, analytic hierarchy process, multiple correlation coefficient, principal component analysis, KLEE method, coefficient of variation, other statistical methods. In these method, some are too subjective, and some are too complex, and some less practical, combine with intercultural communicative competence evaluation, this paper choose KLEE.

KLEE Chinese called ancient forest law, is a scientific approach to the human form of subjective judgment expressed in volume, usually used to determine the evaluation indicator weight. ancient forest law is one of correlation matrix method (RMA, relational matrix analysis). Correlation matrix method is named for its entire program as a matrix arrangement, is a combination of qualitative and quantitative, use matrix form to represent an evaluation value of the evaluation indicator of each alternative, weight and calculated for each program evaluation value, further analysis and comparison, determine the weight and the optimal solution.

According to the literature [8-10], KLEE mathematical model express as follows:

It supposes having $n$-th evaluation indicator, $R_{i}(i=n, n-1, \cdots, 2,1)$ represent the importance of the evaluation after being compared with each other every two get a top-down, that is important. $P_{i}$ indicates project's valuation of the amount of the $i$-th indicator, since the last $n$-th index has no other indicators to compare, so $P_{n}$ don't exist, set up $P_{n}=1$,valuation amount calculate as follows: 
$\left\{\begin{array}{l}P_{n}=1 \\ P_{i-1}=R_{i-1} \times P_{i} \quad(i=n, n-1, \cdots, 2)\end{array}\right.$

To treatment $P_{i}$ by normalized, the index value calculate weight, calculate as follows:

$w_{i}=P_{i} /\left[\sum_{i=1}^{n} P_{i}\right]$

\section{Calculation Results on Indicator Weight}

KLEE weight calculation steps: the evaluation indicator arrange to a row, reference to the following factors, from the bottom to top of adjacent significance deciding factors, calculate the amount of valuation, valuation amount of data will be normalized, obtain weights.

Evaluation indicator system show in figure 1,each secondary indicators to calculate the right weight for level indicators and level indicators for the overall evaluation of the target weight. Article by limited space, only level indicators on the right to re-calculate the overall evaluation of the target as an example to illustrate. The calculation process and results show in Table 1.

Table 1. Weight calculation results on first level evaluation indicator

\begin{tabular}{c|c|c|c:c}
\hline First level indicator & Indicator code & $R_{i}$ & $P_{i}$ & $w_{i}$ \\
\hline Basic qualities & $U_{1}$ & 1.1 & 1.47 & 0.219 \\
\hline Professional morality & $U_{2}$ & 0.7 & 0.92 & 0.137 \\
\hline Physical training & $U_{3}$ & 1.1 & 1.32 & 0.197 \\
\hline Classroom teaching & $U_{4}$ & 1.5 & 1.20 & 0.179 \\
\hline Social services & $U_{5}$ & 0.8 & 0.80 & 0.119 \\
\hline Research ability & $U_{6}$ & $/$ & 1.00 & 0.149 \\
\hline Total & & & 6.71 & 1.00 \\
\hline
\end{tabular}

For each level indicators, press the right major small order of "Basic qualities, Physical training, Classroom teaching, Research ability, Professional morality, Social services", first four target weight reach $74.4 \%$,thus,improve the overall quality of physical education major from this four indicators start.

Each secondary indicators on the right to re-level indicators of the results show in Table 2. 
Table 2. Weight calculation results on second evaluation indicator

\begin{tabular}{c|c|c|c|c:c}
\hline Indicator Name & Code & Weight & Indicator Name & Code & Weight \\
\hline Academic qualifications & $u_{11}$ & 0.227 & Teaching techniques & $u_{41}$ & 0.205 \\
\hline Professional title & $u_{12}$ & 0.256 & Teaching methods & $u_{42}$ & 0.268 \\
\hline Ability and quality & $u_{13}$ & 0.345 & Classroom control & $u_{43}$ & 0.226 \\
\hline Aesthetic cultivation & $u_{14}$ & 0.172 & Teaching effect & $u_{44}$ & 0.301 \\
\hline Dedication & $u_{21}$ & 0.426 & Sports guidance & $u_{51}$ & 0.445 \\
\hline Love students & $u_{22}$ & 0.253 & Fitness consultant & $u_{52}$ & 0.145 \\
\hline Unity and cooperation & $u_{23}$ & 0.177 & Referees and judges & $u_{53}$ & 0.247 \\
\hline Honest Teaching & $u_{24}$ & 0.144 & Exchanges and cooperation & $u_{54}$ & 0.163 \\
\hline Scientific selection & $u_{31}$ & 0.184 & Scientific research topics & $u_{61}$ & 0.121 \\
\hline Special skills & $u_{32}$ & 0.204 & Research methods & $u_{62}$ & 0.182 \\
\hline Training implementation & $u_{33}$ & 0.338 & Research results & $u_{63}$ & 0.377 \\
\hline Director of tournament & $u_{34}$ & 0.274 & Innovation ability & $u_{64}$ & 0.320 \\
\hline
\end{tabular}

The secondary indicator weight show in table 2 weight, improve "Basic qualities" mainly to improve the "Ability and quality" and "Professional title" two indicators, improve "Professional morality" mainly to improve the "Dedication" and "Love students" two indicators, improve "Physical training" mainly to improve "Training implementation" and "Director of tournament" two indicators, improve "Classroom teaching" mainly to improve the "Teaching effect" and "Teaching methods" two indicators, improve "Social services" mainly to improve "Sports guidance" and "Referees and judges" two indicators, improve "Research ability" mainly to improve the "Research results" and "Innovation ability" two indicators.

\section{Conclusion}

There are many factors which effect physical education quality, the most important is the comprehensive ability of Coach. High quality Coach team decided physical education quality level, thereby effect the sustainable development of Chinese sports. Comprehensive evaluation of the Coach is an effective means to improve the ability of Coach. Evaluation of physical research is a systematic project, this study is the evaluation of teaching a new attempt. Any kind of scientific evaluation system to establish and perfect are long-term arduous task. Despite this study's research methods specification establishes the index system, but due to various objective study of the limited conditions, scientific indicator system to be further tested practice.

\section{References}

[1] X. Q. Zhu, H. Zhang, "Evaluation System of College Coach' Professional Quality," Journal of Chengdu Sport University, vol. 40, no. 6, pp. 85-90, 2014.

[2]

Baidu Encyclopedia,

"Education

evaluation,"

http://baike.baidu.com/link?url=VEq1p3ZLoerQrmbdPZSI-Yk5b1-CaptupJ8mt7AhLY1ePHV Vz2mpiq16N-CHVd3z6z5Jp8RYO55MyoZfanLreWaZMr8XfhMtAbWC90hD-sW, 2015-7-20.

[3] Q. T. Zeng, "A Study on the Evaluation System of Chinese Physical Education Teachers," Doctor's degree of Henan University, 2011. 
[4] X. G. Feng, Y. Li, "Overview of Researches on the Methods to Determine the Indicators Weights Evaluation system of Coach in China," Sport Science and Technology, vol. 35, no. 1, pp. 117-118, 2014.

[5] C. C. Zhang, "A Construction of Evaluation System of competence of University Coach," Journal of Jiaying University, vol. 32, no. 2, pp. 88-93, 2014.

[6] José Carlos Sánchez-Prieto, Susana Olmos-Migueláñez, Francisco J. García-Peñalvo, "Informal tools in formal contexts: Development of a model to assess the acceptance of mobile technologies among teachers," Computers in Human Behavior, vol. 10, no. 6, pp. 261-276, 2015.

[7] Roxana Enache, Alina Crisan, "The Analysis of Teachers' Skills and Abilities for the Pre-university System in the Initial and Continuous Training Programs," Procedia - Social and Behavioral Sciences, vol. 114, no. 21, pp. 519-526, 2014.

[8] S. Lan, "Based on KLEE and fuzzy comprehensive evaluation operator cognitive ability assessment," Ergonomics, vol. 16, no. 1, pp. 30-31, 2010.

[9] D. K. Qi, X. Li, H. Zhang, et al, "The Study of Yichun Forest Region Different Levels Forest Ecological Niches Measurement Based on the A. J. Klee," Issues of Forestry Economics, vol. 34, no. 2, pp. 145-148, 2014.

[10] N. Xie, T. Y. Li, "Method based on the ancient forest of new vessels and its application to build market sentiment index," China Water Transport, vol. 33, no. 2, pp. 36-38, 2011. 